\title{
The increasing role of exercise rehabilitation
}

\author{
Khae-Hawn Kim
}

The history of exercise rehabilitation comes from the human desire for health. It was first born when some physiatrists created a concept of "Sports Medicine", the forerunner to the physical medicine and rehabilitation. Physiatrists specialize in restoring the optimal function to people with injuries to the muscles, bones, tissues or nervous system, including those with stroke in particular. Rehabilitation medicine aims to enhance and to restore the functional ability and the quality of life of patients with physical impairment or disability. Physicians who have completed training in this specialty area are called as physiatrists or specialists in rehabilitation medicine. The 'physiatry' was coined by Dr. Frank H. Krusen in 1938, and it was accepted by the American Medical Association in 1946 (Grabois et al., 2000). It made a great progress during the World War II to accommodate a large number of injured soldiers. In the United States, there are six formal subspecialties and these include 1) hospice and palliative medicine, 2) neuromuscular medicine, 3) pain medicine, 4) pediatric rehabilitation, 5) spinal cord injury medicine and 6) sports medicine. The next concept of rehabilitation is much broader. Diseases treated by the rehabilitation therapists include amputation, spinal cord injury, sports injury, stroke, musculoskeletal pain syndromes (e.g., low back pain), fibromyalgia and traumatic brain injury. In the cardiopulmonary rehabilitation, the attempts are made to optimize the functions in patients with heart or lung disease. The management of chronic pain is achieved through multidisciplinary approaches by psychologists, physical therapists, occupational therapists, exercise therapists and anesthesiologists. This may also be accompanied, if applicable, by interventional procedures. For example, stroke patients are often treated by speech and recreational therapy, if applicable, concomitantly with conventional treatment methods. With a special focus on disease prevention and the maintenance of health, the exercise rehabilitation is a safer, more efficient modality as compared with conventional interventions. Moreover, its scope has been gradually extended to provide preventive medicine. With the increased number of aging population and the increased prevalence of chronic diseases, the exercise rehabilitation will become a hot issue; this may further have an impact on both patients and the health care system. Meanwhile, the Journal of Exercise Rehabilitation will provide a forward-looking opportunity in Korea. Thus, we'll strengthen our expertise to improve the current concept of exercise rehabilitation.

Grabois M, Garrison SJ, Hart KA, Lehmkuhl LD. Physical medicine and rehabilitataion: the complete approach. Malden, Massachusetts: Blackwell Science Ltd.; 2000 (ISBN 978-0865425361).

Editor-in-Chief Department of Urology, Gachon University Gil Medical Center, 21 Namdong-daero 774 beon-gil, Namdong-gu, Incheon 405-760, Korea E-mail: kimcho99@gilhospital.com

\footnotetext{
This is an Open Access article distributed under the terms of the Creative Commons Attribution Non-Commercial License (http://creativecommons.org/licenses/by-nc/3.0/) which permits
} unrestricted non-commercial use, distribution, and reproduction in any medium, provided the original work is properly cited. 